\title{
Rethinking Privilege in Teaching English in Japanese Higher Education
}

\author{
Khatereh Hosseininasab \\ Graduate School of Human Sciences, Osaka University, Osaka, Japan \\ https://orcid.org/0000-0001-7460-135X
}

\begin{abstract}
This article addresses the issue of native-speakerism in teaching English in the context of Japanese higher education and the privilege arising from it. Previous research has shown that native speakers are often regarded as highly skilled and qualified teachers in teaching their mother tongue. This has often led to the marginalization of teachers who speak the language they teach as an additional language. In the case of Japan, however, there is doubt about the existence of such a privilege for native-speaker teachers and some studies have shown that native speakers of English do not receive preferential treatment in this context as they are often perceived as replaceable and temporary. The present study aimed to further explore this issue by focusing on the varieties of English Japanese universities expect their teachers to speak. In so doing, the study has investigated hiring policies of Japanese universities with reference to the job advertisements they post on a designated portal. The results of the qualitative thematic analysis indicated that the majority of the advertisements demanded prospective candidates to be native speakers of English, which also meant that this subgroup of teachers has a privilege in landing academic jobs by token of the variety of English they speak. The article suggests that the critical pedagogical approach of teaching English as an international language (TEIL) can mitigate such privilege by raising awareness towards the validity and appropriateness of different varieties of English spoken in the world.
\end{abstract}

Keywords: critical pedagogy; higher education; identity; privilege; teaching English as an international language

\section{Introduction: Teaching English in Japanese higher education}

Ever since English was accepted as the most frequently used language for international communications, it has become a symbol for globalization around the world (Seargeant, 2011). The consequences of this for education systems have been clear in the sense that they are expected to enable students to speak English as this will benefit not only the students but also their nations in the long run. In other words, the rationale for the current emphasis on the development of English language skills is that English is the language of science and technology and those who do not speak it will fail to be competitive in the global job market. That is 
why teaching English as a foreign language (TEFL) has attracted a lot of attention in the education systems of countries in which English is not spoken as the first language. Japan is not an exception in this regard. Pretty similar to many other countries, in Japan also, English is considered essential for participation in global economy (Crystal, 2003). However, there seems to be a mismatch between what is expected and what has actually happened in Japan, as the criticism is often heard that Japanese university graduates do not acquire sufficient English proficiency to meet the needs of the business sector (Aspinall, 2006).

This dissatisfaction with the English proficiency of Japanese youth triggered a change in the course of studies by the Japan Ministry of Education, Sport, Science and Technology (MEXT) in 2003. The last revisions in 2003, also known as the Action Plan, emphasize the development of spoken communication skills in students through increasing secondary school teachers' communicative and pedagogical skills as well as boosting students' motivation and offering alternative methods of assessment for the English component in university entrance examinations (MEXT, 2003, as cited in Nagatomo, 2012). The extent to which such new concerns of MEXT have been successfully translated to the reality of language teaching in Japan is a legitimate question; however, another question to ask is why the ministry has remained indifferent to how English is taught at universities in Japan. Nagatomo (2012) argued that except demanding a change in university entrance exams and an increase in the number of university classes to be taught in English, the Action Plan does not address English education at universities. It makes no mention of the need to increase university teachers' communication and pedagogical skills and neither does it mention the preferred methodology and desired outcome of English education at universities.

The Action Plan, some may argue, is not by definition supposed to address tertiary education. This argument is, of course, fair enough, as the section in charge of the plan is primarily concerned with secondary education in Japan. Nevertheless, it is still a legitimate question to ask MEXT why they have not had similar concerns for post-secondary English education. The failure to instigate reform in English education at tertiary level may partly explain the current dissatisfaction with the proficiency level of Japanese graduates. The failure has become even more imminent after the introduction of the concept of "global jinzai" (global human resource) into the discourse of human resource development in tertiary education. The proposed definition for global jinzai introduces a range of competencies expected to be developed in graduates, of which one of the components is the development of foreign language (usually English) communication skills. According to the objectives stated for this particular component, students are expected to become proficient in English communication while still being able to appreciate the Japanese culture and its values. The burden of realizing these objectives is at least in part on the shoulders of English teachers in universities. In the absence of systematic pre-service and in-service teacher-training programs at tertiary level, however, how have universities coped with the twofold goal of making their students fluent in English while assuring that they deeply understand and appreciate Japanese cultural values? One way to address this issue has been prioritizing Japanese English teachers over native speakers of English, or the so-called Japanization of 
English teaching (Hashimoto, 2000). What Japanization of English has involved is the tendency of many higher education institutions to employ Japanese teachers who teach the language the Japanese way instead of using approaches such as communicative language teaching, which is believed to be a Western approach and even a colonizing force (Phan, 2008). Now, how can such a tendency explain privilege in language teaching in Japan?

Such a policy, one may argue, does not promote native-speakerism as it does not privilege native-speaker teachers of English in Japan. Holliday (2005) defined native-speakerism as an ideology in the language teaching profession "characterized by the belief that 'native-speaker' teachers represent a 'Western culture' from which spring the ideals both of the English language and of English language teaching (ELT) methodology." Considering the aforementioned idea of the Japanization of language teaching, it looks like native-speakerism is not relevant in the Japanese context. Such an argument is also consistent with what some studies have had to offer. Stewart (2005), for instance, believed that such a view has led to the deprofessionalization of native-speaker English teachers, who are often regarded as temporary and replaceable (Nagatomo, 2012). As a result, native-speaker teachers have been reported to face discrimination in hiring practices and are offered short-term and non-renewable contracts (Hayes, 2011). This paper does not intend to negate such arguments. It argues, however, that there are more subtle practices in the field of language teaching in Japan which may privilege certain speakers of English and marginalize others as language teachers. The argument is grounded in the fact that although there are many varieties of English (native and non-native) spoken in the world, conventional ELT practices do not consider them all equally valid and hence privilege speakers of certain varieties of English and not others.

\section{The ideological choice}

Teaching English as a foreign language in the age of globalization has to reflect the new definitions for what it takes to be able to communicate internationally. Not a long time ago it was an unquestionable fact that the purpose of ELT was to enable learners to speak and use English like native English speakers (NESs) do for the obvious reason that this gave the learners the ability to communicate with NESs with ease (McKay, 2002). ELT, thus, has traditionally favored standard American and British varieties of English. The inherent flaw in this argument, however, is the assumption that all individuals who learn English as a foreign or a second language are doing so in order to communicate with NESs. In other words, what this viewpoint misses is that in a world that is constantly becoming globalized, the vast majority of such learners may need to speak English to communicate with other non-native English speakers (NNESs) rather than NESs (Kirkpatrick, 2006). This very issue, along with findings of recent studies regarding the changing status of the English language, has raised a lot of criticism against the traditional approaches to ELT (Marlina, 2014; Matsuda, 2006; McKay, 2012).

Moreover, traditional ELT approaches have also raised ideological and political concerns. As learners are constantly exposed to certain varieties of English (mainly American and British), they end up believing in the supremacy of those 
varieties over the others (Kirkpatrick, 2006). Along the same lines, there are scholars who believe that the traditional approaches to ELT have promulgated a form of linguistic imperialism (Phillipson, 2009) through which Western powers have maintained their colonial positions even in the present time. The recognition of new varieties of English as equally valid ones has been a reaction to traditional ELT in this regard. As Saraceni (2015) concluded, such recognition has created the belief among language teaching scholars that

"[l]earning English need not to be seen as a strenuous journey whose ultimate destination is the achievement of 'native-like' status or a linguistic 'visa' into a special 'inner circle'. Learning English means, above all, making it easier to take part, actively and critically, in the practices and discourses that (re)present, (re)construct and (re-)shape the global and local worlds we live in." (p. 187)

In response to the criticism leveled against traditional ELT, other approaches have emerged in the field that are more critical by nature and more sensitive to the varieties of English spoken in the world. One such approach is English as an international language (EIL).

The proponents of EIL argue that as in a global world there is a much higher possibility for NNESs to communicate with other NNESs in English, language teaching has to embrace the diversity of the Englishes used in the four corners of the world. Emphasis must be placed here on equipping language learners with the skills to negotiate for meaning with other speakers of English who come from different linguistic and cultural backgrounds. Those approaches to language teaching that emphasize an acceptance of different varieties of English thus cry for providing students with more exposure to the diversity of the Englishes spoken around the world (Rose \& Montakantiwong, 2018). In such a context, multilingualism and mutual intelligibility become the ultimate goal in communication instead of native-like competency (McKay, 2012). The emphasis of EIL on accepting different varieties of English and considering them as equally valid leads to giving voice to speakers of those varieties which were once considered inferior to native-speaker norms. Therefore, it can be regarded as a critical pedagogical approach to teaching and learning the English language (Pennycook, 2017). It strives to give voice not only to the speakers of such varieties of English, but also to the teachers who teach English but do not have the privilege of speaking it as their mother tongue.

Sharifian (2009) conceptualized EIL as a paradigm for thinking as well as research and practice in language teaching. Such a paradigm can serve as an analytical tool for educators and researchers to critically revisit the way they conceptualize English and the way they teach English, particularly with reference to the way its use has expanded globally in recent years (Marlina, 2013). EIL is therefore primarily concerned with the way English is used in international settings and by speakers coming from diverse linguistic and cultural backgrounds (Hino, 2019). One important issue to bear in mind here is that EIL is not a single variety of English. It is rather a framework that considers English "with its pluralized forms [...] a language of international and therefore intercultural communication" (Sharifian, 2009, p. 2). It also underlines the importance of linguistic negotiation 
for achieving mutual intelligibility by speakers of English who bring with themselves many different varieties of the language into the interaction. It is against this backdrop that EIL does not prioritize native-speaker teachers of English over other teachers because of the variety of English they speak. However, this theoretical potential of EIL for tackling the native-speaker privilege in ELT has not always translated into practice (Matsuda, 2017). Theory and practice in language teaching have not always been convergent in language teaching, and for various reasons this mismatch has always been present in different areas within language teaching, including teacher education, assessment, and materials development (Tomlinson \& Masuhara, 2018). Back now to the main concern of the present study, the question is whether or not ELT in Japanese higher education is concerned about native-speaker privilege and has the intention to remedy it by resorting to EIL or other similar approaches.

\section{Methodology and data collection}

The present paper reports on a preliminary stage of a larger study investigating the issue of native-speaker privilege in teaching English in Japanese higher education. In this preliminary stage, the main goal has been to explore the prevalent policies of universities in Japan in hiring English language teachers. The question of whether or not privilege is a relevant concern in teaching English in Japanese higher education institutions can be addressed with a number of different approaches. Surveys and interviews targeting language teachers from different backgrounds and cohorts as well as program directors can be among them. The researcher is aware of the need to collect data from all stakeholders involved in teaching English in Japanese universities and intends to do that in the next phases of the study. The present paper, however, is delimited to the exploration of English-teacher hiring policies by doing document analysis on job advertisements posted by Japanese universities on an online portal hosted by Japan Technology and Science Agency, which serves as the main space for looking for academic jobs and positions in Japan.

For this purpose, all language-teaching job advertisements posted by Japanese universities on the portal mentioned above (accessible at https://jrecin.jst.go.jp) in the timespan of early October to early November were documented and analyzed by the researcher. The researcher focused on the qualifications the job advertisements required the applicants to possess as well as other factors, including the type of university (national, public, or private), department (specialized in language teaching or otherwise), job type (part-time or full-time), and employment status (tenured or non-tenured). Twenty-four job advertisements for language-teaching positions were documented and analyzed. Thematic analysis, which is one of the most frequently used techniques in the analysis of qualitative data (Creswell \& Poth, 2018), was employed to explore the required qualifications in the job advertisements. The whole dataset was first coded and then the relationships between codes were explored. As a result, a number of themes emerged that indicated the tendencies of Japanese universities in hiring English teachers.

The data also underwent descriptive statistical analysis to determine the frequency of each of the emerged themes. Furthermore, the researcher used 
cross-tabulation to test possible relationships between the identified variables. Finally, a chi-square test was performed to determine whether the observed relationships between variables were statistically significant.

\section{Results and discussion}

The first stage in the documentation of the whole dataset led to the identification of different types of variables that were referred to in the job advertisements. These variables and their types are introduced in Table 1.

Table 1: Types of variables identified

\begin{tabular}{cl}
\hline Type & \multicolumn{1}{c}{ Variables } \\
\hline Institutional & University type, department \\
Job-related & Job type, employment status \\
Qualifications & $\begin{array}{l}\text { Education, professional skills, interpersonal skills, } \\
\text { nationality, Japanese language skills, English language } \\
\text { skills, teaching experience, residence status, aspiration }\end{array}$ \\
\hline
\end{tabular}

As Table 1 indicates, the 13 variables identified in the job advertisements posted on the portal could be categorized into three major types, namely institutional, job-related and qualifications. There were also other categories in the advertisements, including documents to be submitted or the method of submission, but as these issues were not relevant to the issue of privilege, they were excluded from the list of variables. From this list, institutional and jobrelated variables were included in all job advertisements in the dataset. However, the variables in the qualifications category were present in some advertisements and absent in others. That is to say, the qualifications required differed from one job advertisement to another. The variables included in Table 1, therefore, contain all variables identified in the whole dataset.

To estimate the priorities of Japanese universities in hiring English teachers, the frequency of occurrence of all variables in the qualifications category was calculated. However, for the sake of space, Tables 2 and 3 present the calculated frequencies and percentages only for the two variables that are more directly related to the issue of privilege with regard to the variety of English spoken by the teachers. These two variables are nationality and English language skills. Whereas some of the job advertisements did not mention looking for any particular nationality, others stated that they were exclusively hiring teachers either from countries in which English is spoken as the first language (NESs) or from Japan. Moreover, in terms of required English proficiency, whereas some of the advertisements did not refer to any required proficiency level for the prospective applicants, others either required sufficient proficiency or native-like proficiency. Both of these variables (nationality and English language skills) were relevant to the theme of this research, which is the privilege arising from the variety of English spoken by teachers. Table 2 summarizes the calculated frequencies for three representations of the nationality variable. 
Table 2: Frequency of variables related to nationality of prospective applicants

\begin{tabular}{cccc}
\hline Nationality & Frequency & Percentage & $\begin{array}{c}\text { Cumulative } \\
\text { percentage }\end{array}$ \\
\hline Not mentioned & 9 & 37.5 & 37.5 \\
Native English speaker & 13 & 54.2 & 91.7 \\
Native Japanese speaker & 2 & 8.3 & 100 \\
Total & 24 & 100 & \\
\hline
\end{tabular}

As the figures in Table 2 indicate, more than half of the job advertisements (54.2\%) required prospective applicants to be native speakers of English. There was no indication in the advertisements as of what being a native speaker of English means. For instance, it was not clear whether a teacher born in a country in which English is not the first language but raised in an English-speaking country would be regarded as a native speaker. Despite this, 13 universities (54.2\%) sought only native speakers for their English-teaching positions. In addition, there were two universities $(8.3 \%)$ that looked for Japanese applicants exclusively, whereas the remaining nine universities $(37.5 \%)$ did not refer to nationality as a criterion for employment. Table 3 shows the frequency of three different representations of the English language skills variable.

Table 3: Frequency of variables related to English language skills of prospective applicants

\begin{tabular}{cccc}
\hline English language skills & Frequency & Percentage & $\begin{array}{c}\text { Cumulative } \\
\text { percentage }\end{array}$ \\
\hline Not mentioned & 11 & 45.8 & 45.8 \\
Sufficient proficiency & 7 & 29.2 & 75 \\
Native-like proficiency & 6 & 25 & 100 \\
Total & 24 & 100 & \\
\hline
\end{tabular}

As Table 3 suggests, 11 advertisements (45.8\%) took for granted that an applicant for an English-teaching job must be proficient in the language. This can probably be explained by the fact that these universities were among those that looked for native-speaker teachers. From the remaining universities, seven (29.2\%) looked for applicants with English skills sufficient for teaching the language, and the other six $(25 \%)$ required applicants with native-like proficiency in English. The advertisements in this latter group, however, did not specify what exactly they meant by native-like proficiency. What is interesting here is that besides the 13 universities which exclusively sought to hire native-speaker teachers (Table 2), six more universities had the normative requirement that applicants must be able to speak English similar to native speakers of English. This reference to nativespeaker norms English use lies at the center of the argument for the presence of privilege with reference to the variety of English spoken by teachers in Japan and will be discussed in the subsequent sections of this paper. 
In line with the goal of the study and after the descriptive analysis of the data, the researcher sought to find relationships between the qualification variables and the institutional and job-related variables. The data were cross-tabulated and a chi-square test was performed to evaluate the significance of potential relationships among the variables. The results indicated that there was no significant relationship between any of the qualification variables and the institutional and job-related variables. This means, for example, that the type of university or the department did not influence the tendency to hire native-speaker teachers or otherwise. There was only one exception to this, however. The analysis indicated that there was a significant relationship between the nationality variable and the employment status variable. Tables 4 and 5 respectively summarize the results of the cross-tabulation and chi-square test for these two variables.

Table 4: Cross-tabulation of nationality and employment status

\begin{tabular}{|c|c|c|c|c|c|}
\hline & & & \multicolumn{3}{|c|}{ Employment status } \\
\hline & & & Non-tenured & Tenured & Total \\
\hline \multirow[t]{9}{*}{ Nationality } & Not mentioned & Count & 5 & 4 & 9 \\
\hline & & Expected count & 7.1 & 1.9 & 9.0 \\
\hline & & $\%$ within nationality & $55.6 \%$ & $44.4 \%$ & $100.0 \%$ \\
\hline & Native English & Count & 13 & 0 & 13 \\
\hline & & Expected count & 10.3 & 2.7 & 13.0 \\
\hline & & $\%$ within nationality & $100.0 \%$ & $0 \%$ & $100.0 \%$ \\
\hline & Native Japanese & Count & 1 & 1 & 2 \\
\hline & & Expected count & 1.6 & .4 & 2.0 \\
\hline & & $\%$ within nationality & $50.0 \%$ & $50.0 \%$ & $100.0 \%$ \\
\hline \multirow[t]{3}{*}{ Total } & & Count & 19 & 5 & 24 \\
\hline & & Expected count & 19.0 & 5.0 & 24.0 \\
\hline & & $\%$ within nationality & $79.2 \%$ & $20.8 \%$ & $100.0 \%$ \\
\hline
\end{tabular}

Table 4 summarizes the distribution of the three representations of the nationality variable in non-tenured and tenured English-teaching positions. Of particular interest to the topic of this research is the fact that all of the universities that looked at hiring native English teachers had non-tenured positions available. On the other hand, $44.9 \%$ of the universities that did not mention a particular nationality as an employment requirement offered tenured positions to successful candidates. Table 5 shows the results of the chi-square test to explore whether this observed relationship is statistically significant.

Table 5: Chi-square tests to explore the relationship between nationality and employment status

\begin{tabular}{lccc}
\hline & Value & $\mathrm{df}$ & Asymp. Sig. (2-sided) \\
\hline Pearson chi-square & $7.495^{\mathrm{a}}$ & 2 & .024 \\
Likelihood ratio & 9.426 & 2 & .009 \\
Linear-by-linear association & 1.542 & 1 & .214 \\
N of valid cases & 24 & & \\
\hline
\end{tabular}




\begin{tabular}{lccc}
\hline & Value & $\mathrm{df}$ & Asymp. Sig. (2-sided) \\
\hline Pearson chi-square & $7.495^{\mathrm{a}}$ & 2 & .024 \\
Likelihood ratio & 9.426 & 2 & .009 \\
Linear-by-linear association & 1.542 & 1 & .214 \\
\hline
\end{tabular}

a. Four cells $(66.7 \%)$ have an expected count of less than 5 . The minimum expected count is .42 .

To interpret the results of the chi-square test, a null hypothesis was first developed. According to the null hypothesis, there is no significant relationship between the nationality and employment status variables. As can be seen in Table 5, however, the $p$ value in the calculated figures is less than $0.05(p=0.024)$, and therefore the null hypothesis is rejected. In other words, universities that preferred to hire NESs offered the applicants only non-tenured positions and this relationship was statistically significant.

What can be inferred from these results is twofold. In the first place, the results indicate that hiring policies of Japanese universities grant privilege to native speakers of English. Teachers in this subgroup have more job opportunities to choose from compared to their colleagues who are either Japanese or non-Japanese and non-native speakers of English. This seems to be in line with what previous research on native-speakerism has had to offer (Shiroza, 2020). Furthermore, the data also implies that in the job advertisements documented in this study, English teachers are regarded as either native speakers or Japanese applicants who are obviously non-native speakers of English. In other words, a third possible category, namely teachers who are neither native speakers of English nor Japanese, seems to have been excluded from the advertisements as well as previous research.

The second issue inferred from the results is that privilege cannot be regarded as an absolute concept. Based on the results, although there appears to be privilege for native-speaker teachers with reference to the nationality variable in the hiring policies, employment status of teachers as referred to by universities proves the contrary. Native-speaker teachers were mostly offered non-tenured and limited-term contracts, which left them in a disadvantaged position compared to their Japanese colleagues. This finding corroborates what previous research has found about discrimination in the workplace against different groups of foreign university teachers (Hayes, 2011; Nagatomo, 2012; Nagatomo, Brown, \& Cook, 2020). The problem seems to be clear now: privilege exists in the field of language teaching in Japanese higher education. The following two sections deal with the ways this problem can be further studied and addressed.

\section{The relevance of studying teacher identity to challenge privilege}

Understanding policies behind language teaching practices is indeed key to exploring privilege in language teaching. Of equal importance, however, is making sense of who language teachers are and how they construct or perceive this privilege (Varghese, Morgan, Johnston, \& Johnson, 2005). Therefore, understanding "the professional, cultural, political, and individual identities which [language teachers] claim or which are assigned to them" (Varghese et al., 
2005 , p. 22) is the very first step in studying privilege in the language classroom. Language teacher identities are discursively constructed by the self as well as the discourses in the society and through the teachers' interactions with their students, pedagogy, curriculum, and assessment (Glodjo, 2017).

Duff and Uchida (1997) studied language teacher identity in tertiary education in Japan and found that although their participants considered themselves teachers of the English language and not the culture, they were actually teaching culture in line with their sociocultural identification. The study found that "language teachers are very much involved in the transmission of culture, and each selection of videos, newspaper clippings, seating plans, activities, and so on has social, cultural, and educational significance" (Duff \& Uchida, 1997, p. 476). What is more, as teaching the elements of culture is embedded in the teaching of the subject matter in the classroom, it positions students in a particular way either intentionally or unintentionally. The very fact that teachers' intentional or unintentional pedagogical choices and preferences can influence student positioning and possibly identity formations opens up the issue of privilege in the language classroom.

A number of scholars (Block, 2014; Vandrick, 2014; Yazan \& Rudolph, 2018) have addressed the issue of identity and privilege with reference to Bourdieu (1986) notion of social reproduction which results from "the cultural and symbolic capital in a particular field and habitus" (Glodjo, 2017). It is assumed in these studies that the dominant group that possesses the social and cultural capital defines normality in the habitus. That is to say, the values, beliefs, and lifestyle of the dominant group become the norm in a habitus, and this normality is reproduced constantly by the dominant group. As it is reproduced constantly, it becomes legitimate to the extent that it can no longer be easily discarded or even criticized. Similarly, in the social context of the language classroom, the social reproduction of the values of the dominant group creates a "hidden curriculum" which shows "the tacit ways in which knowledge and behavior get constructed, outside the usual course materials and formally scheduled lessons" (McLaren, 2009, p. 75). As a result, those outside the dominant group are considered as other and are silenced to the extent that they are expected to follow the standards of the dominant group. In other words, individuals outside the dominant group are conditioned to be subordinate to those who possess the social and cultural capital. They are conditioned to "behave in certain ways, make certain interpretations about their place in society and the way the world functions, and adjust their expectations of their future opportunities accordingly" (Sanders \& Mahalingam, 2012, p. 114).

As discussed earlier, the role of English is constantly changing in today's globalized world. While not a long time ago it was considered as an unquestionable fact that learners of English have to imitate and emulate NESs in order to learn the language, recent critical approaches to language education, including EIL, have shown that native-like proficiency is neither a requirement nor a desired attribute for individuals who seek to communicate in English internationally. The number of NNESs who need to interact with other NNESs is currently increasing and this entails raising awareness of the English spoken by 
NNESs rather than narrowly focusing on how NESs use the language and see the world. This, however, is not consistent with the realities of the language classroom. Evidence for this claim can be found in the textbooks and audiovisual language-learning materials published by well-known publishers, as well as international tests of English such as TOEFL and IELTS. Many published language-learning materials still primarily manifest the culture and lifestyle of a dominant group in Anglophone countries (Kazemi, Asadi \& Davatgari, 2017). Text and audiovisual supplements used in these materials almost exclusively uphold standard American, British, and Australian varieties of English as valid, normal, and standard and that must to be followed by English learners. The same is true about international tests of English. It is rare, if not impossible, for such tests to include Indian, Malaysian, South African, or even Arabic varieties of English. Such varieties of English seem to have been totally neglected and left behind. However, in the real world, a Japanese learner of English may need to interact with speakers of English from all these countries (and more) and hence has to be prepared for using and understanding English in such contexts.

For various historical reasons, the countries in which English is spoken as the first language hold economic, political, military, and even cultural dominance in many parts of the world. This has led to a state in which they are looked up to by many nations as having high levels of social and cultural capital. As they are wealthy nations, they have been controlling media as well, and this has led to the reproduction of the status associated with them. This may explain why, despite the fact that English is an international language in the world now, it is taken for granted that the native-speaking countries have the ownership of English. Such a discourse obviously operates in favor of a system that seeks to create outsiders (speakers of non-native varieties of English) that are subordinate to particular ingroups (NESs). One important question seems to have remained unanswered yet: how can the language classroom be liberated from such biased classifications? One way to address this issue is to resort to critical pedagogy.

Giroux (2009), who is believed to be the founding father of critical pedagogy alongside Freire, argued that a prerequisite to such a liberation is the presence of teachers who can critically reflect on their positionality, identity and privilege. $\mathrm{He}$ calls such a teacher a "transformative intellectual [...] who exercises forms of intellectual and pedagogical practice [...] arguing that schooling represents both a struggle for meaning and a struggle over power relations" (Giroux, 2009, p. 439). This has clear implications for teacher-education research showing the need for training teachers who can critically reflect on the way their identity is constructed, and value differences between their students and themselves as resources rather than deficits (Glodjo, 2017).

\section{A solution: EIL as critical pedagogy}

Central to the idea of critical pedagogy (Freire, 1999) is transforming the conception of knowledge as apolitical and neutral in education. It aims at empowering the students by teaching them how to challenge and defy domination and dominating discourses of power in society. From a linguistic point of view, EIL shares this concern as well. It strives to give voice to speakers of non-native varieties of English. Its point of departure is the contention that all 
varieties of English are equally valid, and English should be taught without an undue reference to how NESs use it. Also, it emphasizes the fact that not all people who wish to learn English have the intention to learn and adopt the AngloAmerican culture, lifestyle, and worldview. They may well have instrumental motivation to learn the language as a tool for communication with other speakers of the language around the world. Pennycook (2017) thus argued that "[n]either the version of language produced by the discourse of ElL, nor the discourse of EIL itself can be accepted as neutral, for both language and discourse always imply a politics" (p. 301). The politics EIL stands against are that of superiority and dominance of certain varieties of English and their speakers (including the teachers who speak them and teach them) over the others. Broadly defined, critical pedagogy is a desire for bringing about social change through education, and so is the case with EIL. Schools, and the language classroom by extension, therefore cannot be regarded as a space for transmitting a neutral body of knowledge to the students or language learners. Akin to critical pedagogy that takes schools as areas for constant social, political, and cultural struggle, EIL rejects the traditional approaches of language teaching that deal with the language-learning process merely as a psycholinguistic one isolated from its social and cultural context.

Not reckoning the principles of critical pedagogy, Giroux (1998) argued that we need to oppose the notion of curriculum knowledge as sacred and impeccable and explore the many reasons why certain types of culture and knowledge are given precedence in educational settings. From an EIL perspective, for instance, the question would be why certain accents of English from particular varieties, values and cultures associated with them and their sociolinguistic norms are considered "standard" while others are not. In such an environment, teachers need to be what Geroux called "transformative intellectuals". A similar statement was made by EIL proponents (Hino, 2019; McKay, 2012; Renandya, 2012), who argued that teachers in this changing sociolinguistic landscape of English need to promote multiculturalism in the language classroom and decentralize the native-speaker norms governing language use. That is what makes an exploration of the teachers' perceptions and classroom practice relevant and significant.

\section{Conclusion}

This paper addressed the issue of privilege and how it may exist in teaching English at higher education institutions in subtle and less noticeable ways. Particularly in the case of Japan, despite research showing that native-speaker teachers of English in Japanese universities do not enjoy any privilege and are even faced with discrimination, the results of this study showed the contrary. It was found that privilege in hiring policies of Japanese universities lies in the variety of English teachers speak The native-speaker varieties of English showcased in language-teaching materials used in Japanese higher education institutions as well as elsewhere result in the belief that the desired varieties of English to be learned by learners are those spoken by NESs. As a result, Japanese universities are more interested in hiring native-speaker teachers. Whereas traditional ELT approaches have by and large remained insensitive to this issue, EIL and other similar approaches have addressed it. While privilege may well exist in other subtle ways that future research is encouraged to explore, this study 
stayed focused on privilege arising from native-speaker-oriented hiring policies. It suggested the adoption of EIL principles to teach English in higher education as it both offers a more realistic outlook towards the way English is used in today's globalized world and challenges the privilege it produces for speakers of certain varieties of English. In this sense, EIL can be regarded as a critical pedagogical approach to teaching English as it strives, in part, to bring about equity and inclusiveness in the profession.

\section{References}

Aspinall, R. W. (2006). Using the paradigm of "small cultures" to explain policy failure in the case of foreign language education in Japan. Japan Forum, 18(2), 255-274. doi:10.1080/09555800600731197

Block, D. (2014). Social class in applied linguistics. New York: Routledge. doi:10.4324/9781315871141

Bourdieu, P. (1986). The forms of capital. In D. W. O'shea, \& J. G. Richardson (Eds.), Handbook of theory of research for sociology of education (pp. 241-258). New York: Greenwood Press. doi:10.2307/2069964

Creswell, J. W., \& Poth, C. N. (2018). Qualitative inquiry \& research design: Choosing among five approaches. Los Angeles: Sage.

Crystal, D. (2003). English as a global language. Cambridge: Cambridge University Press.

Duff, P. A., \& Uchida, Y. (1997). The negotiation of teachers' sociocultural identities and practices in postsecondary EFL classrooms. TESOL Quarterly, 31(3), 451-486. doi: $10.2307 / 3587834$

Freire, P. (1999). Pedagogy of the oppressed. New York: Continuum.

Giroux, H. A. (1998). Education in unsettling times: Public intellectuals and the promise of cultural studies. In D. Carlson, \& M. Apple (Eds.), Power/knowledge/pedagogy, the meaning of democratic education in unsettling times (pp. 40-60). CO: West view Press. doi:10.4324/9780429498060-1

Giroux, H. A. (2009). Teacher education and democratic schooling. In A. Darder, M. P. Baltodano, \& R. D. Torres (Eds.), The critical pedagogy reader (pp. 438-459). New York: Routledge.

Glodjo, T. (2017). Deconstructing social class identity and teacher privilege in the second language classroom. TESOL Journal, 8(2), 342-366. doi:10.1002/tesj.273

Hashimoto, K. (2000). 'Internationalisation' is 'Japanisation': Japan's foreign language education and national identity. Journal of Intercultural Studies, 21(1), 39-51. doi.org/10.1080/07256860050000786

Hayes, B. E. (2011). Hiring criteria for Japanese university English-teaching faculty. In T. Skutnabb-Kangas (Ed.), The native speaker English teacher: From exclusion to inclusion. Linguistic diversity and language rights series (pp. 270-287). Abingdon: Multilingual Matters. doi:10.21832/9781847698704-013

Hino, N. (2019). EIL education for the expanding circle: A Japanese model. Oxon: Routledge.

Holliday, A. (2005). The struggle to teach English as an international language. Oxford: Oxford University Press.

Kazemi, S., Asadi, A. N., \& Davatgari, A. H. (2017). Manifestations of globalization and linguistic imperialism in English language teaching and materials preparation: Ideology in the international ELT textbooks. Research in English Language Pedagogy, $5(2), 223-246$.

Kirkpatrick, A. (2006). Which model of English: Native-speaker, nativized, or lingua franca. In R. Rubdy, \& M. Saraceni (Eds.), English in the world: Global rules, global roles (pp. 71-83). London: Continuum. doi:10.1093/applin/amn015 
Marlina, R. (2013). Teaching English as an international language: Voices from an Australian university classroom (Unpublished doctoral dissertation). Monash University, Melbourne, Australia.

Marlina, R. (2014). The pedagogy of English as an international language: More reflections and dialogues. In R. Marlina, \& R. A. Giri (Eds.), The pedagogy of English as an international language: Perspectives from scholars, teachers, and students (pp. 1-19). Cham: Springer. doi:10.1017/s0266078419000488

Matsuda, A. (2006). Negotiating ELT assumptions in EIL classroom. In J. Edge (Ed.), (Re)locating TESOL in an age of empire (pp. 158-170). Basingstoke: Palgrave MacMillan. doi:10.1057/9780230502239

Matsuda, A. (2017). Preparing teachers to teach English as an international language. Bristol: Multilingual Matters. doi:10.21832/9781783097036

McKay, S. L. (2002). Teaching English as an international language: Rethinking goals and approaches. Oxford, England: Oxford University Press.

McKay, S. L. (2012). Teaching materials for English as an international language. In A. Matsuda (Ed.), Teaching English as an international language: Principles and practices (pp. 70-83). Bristol: Multilingual Matters. doi:10.21832/9781847697042

McLaren, P. (2009). Critical pedagogy: A look at the major concepts. In A. Darder, M. P. Baltodano, \& R. D. Torres (Eds.), The critical pedagogy reader (pp. 61-83). New York, NY: Routledge.

Nagatomo, D. H. (2012). Exploring Japanese university English teachers professional identity. Bristol: Channel View Publications. doi: 10.21832/9781847696489

Nagatomo, D. H., Brown, K., \& Cook, M. (2020). Foreign female English teachers in Japanese higher education: Narratives from our quarter. Tokyo: Independent Publication. doi:10.47908/11

Pennycook, A. (2017). The cultural politics of English as an international language. Milton: Taylor \& Francis. doi:10.4324/9781315225593

Phan, L. H. (2008). Teaching English as an international language: Identity, resistance and negotiation. Clevedon: Multilingual Matters. doi:10.21832/9781847690500

Phillipson, R. (2009). Linguistic imperialism. Oxford: Oxford University Press. doi:10.4324/9780203857175

Renandya, W. A. (2012). Teacher roles in EIL. The European Journal of Applied Linguistics and TEFL, 1(2), 65-80.

Rose, H., \& Montakantiwong, A. (2018). A tale of two teachers: A duo ethnography of the realistic and idealistic successes and failures of teaching English as an international language. RELC Journal, 49(1), 88-101. doi:10.1177/0033688217746206

Sanders, M. R., \& Mahalingam, R. (2012). Under the radar: The role of invisible discourse in understanding class-based privilege. Journal of Social Issues, 68(1), 112-127. doi:10.1111/j.1540-4560.2011.01739.x

Saraceni, M. (2015). World Englishes: A critical analysis. New York: Bloomsbury Publishing. doi:10.1515/jelf-2016-0009

Seargeant, P. (2011). English in Japan in the era of globalization. Basingstoke: Palgrave Macmillan. doi:10.1057/9780230306196

Sharifian, F. (2009). English as an international language: Perspectives and pedagogical issues. Clevedon: Multilingual Matters. doi:10.21832/9781847691231-004

Shiroza, S. (2020). Changing language, continuing discourse: A shift toward ELF and persistent native-speakerism in Japan's ELT policy. In R. A. Giri, A. Sharma, \& J. D'Angelo (Eds.), Functional variations in English. Multilingual education. Springer, Cham. doi.org/10.1007/978-3-030-52225-4_18 
Stewart, A. (2005). Teaching positions: A study of identity in English language teachers in Japanese higher education (Unpublished PhD thesis). University of London, London, England.

Tomlinson, B., \& Masuhara, H. (2018). The complete guide to the theory and practice of materials development for language learning. Oxford: Wiley Blackwell.

Vandrick, S. (2014). The role of social class in English language education. Journal of Language, Identity and Education, 13(2), 85-91. doi:10.1080/15348458.2014.901819

Varghese, M., Morgan, B., Johnston, B., \& Johnson, K. A. (2005). Theorizing language teacher identity: Three perspectives and beyond. Journal of Language, Identity $\mathcal{E}$ Education, 4(1), 21-44. doi:10.1080/15348458.2014.901819

Yazan, B., \& Rudolph, N. (2018). Criticality, teacher identity, and (in)equity in English language teaching. Issues and implications. Cham: Springer International Publishing. doi:10.1007/978-3-319-72920-6 